\title{
Стрессовые реакции пациентов с онкологической патологией до и после специальных методов лечения: пилотные исследования
}

\author{
${ }^{1}$ Национальный педагогический университет им. М.П. Драгоманова, Киев \\ ${ }^{2}$ Национальный институт рака, Киев \\ Получено 28.01.2020 \\ Принято в печать 20.02.2020 \\ DOI:10.32471/clinicaloncology.2663-466X.36-4.26790
}

\begin{abstract}
Введение. Грудная железа, яичники и шейка матки являются атрибутами женского тела, и их потеря после операции по поводу рака, безусловно, считается сильным психотравмирующим фактором. Объект и методы исследования. Для оценки психологического статуса в наших исследованиях использовали Госпитальную шкалу тревоги и депрессии (Hospital Anxiety and Depression Scale - HADS), потому что ее психометрические качества широко продемонстрированы в валидационных исследованиях в клинической онкологии. Результаты. Выраженность стрессовых реакций на диагноз "рак" зависела как от специальных методов лечения, так и от возраста пациентов. Наиболее сильное проявление депрессии и тревоги наблюдалось у женщин репродуктивного возраста на момент верификации диагноза. Выводы. Полученные пилотные результаты указывают на необходимость коррекции психологического состояния пациентов со злокачественными новообразованиями, особенно на стадии установления диагноза.
\end{abstract}

Ключевые слова: депрессия; тревога; рак грудной железы; рак яичников; шейки матки; репродуктивный возраст.

\section{ВВЕДЕНИЕ}

В настоящее время все чаще внимание обращают на одну из важнейших задач, стоящих перед здравоохранением, а именно - вопрос о роли психологических факторов в развитии и течении соматических заболеваний $[1,2]$. Не исключением является и онкология. Повышение распространенности онкологических заболеваний, эффективность лечения и дальнейший прогноз зависят не только от физических, химических, генетических и физиологических факторов онкогенеза. Он может быть обусловлен и существованием других (психогенных) факторов, влияющих на течение патологического процесса. Известно, что существует тесная связь эффективности противоопухолевого лечения с психоэмоциональным статусом пациентов, которая в нашей стране практически не учитывается [3-6].

Во всех ведущих онкологических клиниках мира обязательным является психологическое сопровождение онкологических больных, как на этапе диагностики, так и в процессе лечения [7-9]. Поэтому актуальность исследований по применению методик психоэмоциональной диагностики и последующей коррекции у онкологических больных не вызывает сомнений.

Целью настоящих исследований являлось изучение показателей депрессии и тревоги у больных раком грудной железы (РГЖ), яичников (РЯ) и шейки матки (РШМ) как на этапе диагностики, так и после проведения специальных методов лечения.

\section{ОБЪЕКТ И МЕТОДЫ ИССЛЕДОВАНИЯ}

Исследования проведены в отделениях опухолей грудной железы и реконструктивной хирургии и онкогинекологии Национального института рака. Под нашим наблюдением находились 17 пациенток с диагнозом РГЖ T2N1M0-T3N $1 \mathrm{M} 0$ в возрасте 25-52 лет (средний возраст - 35,5 года, медиана - 42,3 года). Контрольную группу составили 5 женщин такой же возрастной группы с доброкачественными заболеваниями грудной железы (контроль 1). Группу онкогинекологических заболеваний составили 6 больных с РЯ T2N0M0-T3N1M0 (средний возраст - 43,7 года, медиана 40,6 года) и 7 больных РШМ T2N0M0-T2N1M0 в возрасте $31-46$ лет (средний возраст - 38,5 года, медиана - 38, 1 года). Контролем к этой группе больных были 4 пациентки с доброкачественными заболеваниями яичников и шейки матки (контроль 2). В группе больных РГЖ 4 пациентки не получали специальных методов лечения (только госпитализированы) (группа РГЖ-0). У 6 была проведена неоадъювантная полихимиотерапия (НАПХТ) с последующей секторальной резекцией или мастэктомией (группа РГЖ-1). Остальные 7 больных проходили адъювантную полихимиотерапию (АПХТ) (группа РГЖ-2). В группе больных РЯ 2 пациентки не получали специального лечения (только госпитализированы: группа РЯ-0), 3 - проходили НАПХТ с последующим оперативным лечением (группа РЯ-1) и 2 больных с послеоперационной АПХТ (группа РЯ-2). У пациентов с РШМ 2 только госпитализированы (лечение не получали; группа РШМ-0), 2 пациента с НАПХТ и последующим оперативным лечением (группа РШМ-1) и 2 больных с послеоперационной АПХТ (группа РШМ-2). У всех исследуемых основной и контрольных групп проведено анкетирование с использованием Госпитальной шкалы тревоги и депрессии (HADS) [3, 5, 7].

Полученные результаты обрабатывали с использованием методов статистического анализа с применением критерия Пирсона $\left(\chi^{2}\right)$. Достоверными считали значения при уровнях $\mathrm{p}<0,05$.

\section{РЕЗУЛЬТАТЫ}

В результате проведенных исследований установлено, что наиболее высокие уровни депрессии и тревоги наблюдались у женщин, узнавших свой диагноз до проведения специальных методов лечения (табл. 1).

Таблица 1. Показатели депрессии и тревоги у женщин с верифицированным диагнозом РГЖ, РЯ и РШМ до специальных методов лечения

\begin{tabular}{lccc}
\hline \multicolumn{1}{c}{ Диагноз } & $\begin{array}{c}\text { Количество } \\
\text { больных }\end{array}$ & $\begin{array}{c}\text { Депрессия, } \\
\mathbf{n}(\%)\end{array}$ & $\begin{array}{c}\text { Тревога, } \\
\mathbf{n}(\%)\end{array}$ \\
\hline РГЖ-0 & 4 & $3(75 \pm 24,5)^{*}$ & $4(100 \pm 28,6)^{*}$ \\
Контроль 1 & 5 & $0(0,0)$ & $2(40,0 \pm 17,8)$ \\
РЯ-0 & 2 & $1(50 \pm 28,4)^{*}$ & $2(100 \pm 42,1)^{* *}$ \\
РШМ-0 & 2 & $2(100 \pm 17,6)^{*}$ & $2(100 \pm 19,3)^{* *}$ \\
Контроль 2 & 4 & $0(0,0)$ & $1(25,0 \pm 17,2)$ \\
\hline
\end{tabular}

${ }^{*} \mathrm{p}<0,05$ по сравнению с контролем $1 ;{ }^{* \star} p<0,05$ по сравнению с контролем 2 .

Назначение НАПХТ приводило к некоторому снижению уровня депрессии и тревоги, несмотря на токсические проявления этой методики. У женщин появлялась надежда на благополучный 
исход заболевания. Этот феномен касался как женшин с РГЖ, так и пациенток с онкогинекологической патологией (табл.2)

Таблица 2. Показатели депрессии и тревоги у женщин с РГЖ и онкогинекологической патологией после НАПХТ и оперативного лечения.

\begin{tabular}{lccc}
\hline \multicolumn{1}{c}{ Диагноз } & $\begin{array}{c}\text { Количество } \\
\text { больных }\end{array}$ & $\begin{array}{c}\text { Депрессия, } \\
\mathbf{n}(\%)\end{array}$ & $\begin{array}{c}\text { Тревога, } \\
\mathbf{n}(\%)\end{array}$ \\
\hline РГЖ-0 & 4 & $3(75,0 \pm 24,5)$ & $4(100 \pm 28,6)$ \\
РГЖ-1 & 6 & $2(33,3 \pm 10,3)$ & $3(50 \pm 19,7)$ \\
РЯ-0 & 2 & $1(50,0 \pm 33,3)$ & $2(100 \pm 42,1)$ \\
РЯ-1 & 3 & $1(33,3 \pm 19,6)$ & $2(66,6 \pm 20,6)$ \\
РШМ-0 & 2 & $2(100 \pm 17,6)$ & $2(100 \pm 19,3)$ \\
РШМ-1 & 2 & $1(50,0 \pm 33,3)$ & $1(50,0 \pm 33,3)$ \\
\hline
\end{tabular}

Оперативное лечение еще больше снижало показатели HADS у исследуемых женщин. По-видимому, у пациенток укреплялась уверенность в благоприятном решении проблемы. Применение АПХТ существенно не влияло на показатели HADS как у женщин с РГЖ, так и у пациентов с онкогинекологическим раком по сравнению с группой НАПХТ и оперативным лечением (табл. 3). Можно предположить, что выраженная токсичность применяемых противоопухолевых препаратов и связанные с ними явления токсикоза и дискомфорта несколько снижали уверенность в благоприятном прогнозе.

Таким образом, можно заключить, что наиболее существенный вклад в развитие явлений депрессии и тревоги по показателям HADS у пациенток вносит ознакомление с результатами верификации заболевания.

Таблица 3. Показатели депрессии и тревоги у женщин после оперативного лечения и АПХТ по поводу РГЖ, РЯ и РШМ

\begin{tabular}{lccc}
\hline \multicolumn{1}{c}{ Диагноз } & $\begin{array}{c}\text { Количество } \\
\text { больных }\end{array}$ & $\begin{array}{c}\text { Депрессия, } \\
\mathbf{n}(\%)\end{array}$ & $\begin{array}{c}\text { Тревога, } \\
\mathbf{n}(\%)\end{array}$ \\
\hline РГЖ-1 & 6 & $2(33,3 \pm 10,3)$ & $3(50,0 \pm 19,7)$ \\
РГЖ-2 & 7 & $2(28,6 \pm 11,5)$ & $4(57,1 \pm 23,2)$ \\
PЯ-1 & 3 & $1(33,3 \pm 19,6)$ & $2(66,6 \pm 20,6)$ \\
PЯ-2 & 2 & $1(50 \pm 33,3)$ & $2(50,0 \pm 33,3)$ \\
РШМ-1 & 2 & $1(50 \pm 33,3)$ & $1(50,0 \pm 33,3)$ \\
РШМ-2 & 2 & $1(50 \pm 33,3)$ & $1(50,0 \pm 33,3)$ \\
\hline
\end{tabular}

Следует отметить, что наиболее выраженные явления депрессии и тревоги отмечались у более молодых женщин, независимо от локализации опухолевого процесса. По-видимому, это связано с тем, что грудная железа, яичники и шейка матки являются признаками женского тела, и их потеря вследствие хирургического вмешательства по поводу онкопатологии, безусловно, является сильным психотравмирующим фактором. А это, в свою очередь, может обусловливать процессы метастазирования, отягощающие прогноз заболевания [8-11]. В более пожилом возрасте у пациенток показатели депрессии и тревоги были менее значимыми на всех этапах онкологического сопровождения (табл. 4). Таким образом, определение психологического статуса у больных злокачественными новообразованиями до и после противоопухолевого лечения может быть использовано для подбора методов последующей психологической реабилитации этих пациентов.

Таблица 4. Показатели депрессии и тревоги у женщин с онкологической патологией в разных возрастных группах

\begin{tabular}{lcccc}
\hline Диагноз & $\begin{array}{c}\text { Возрастная } \\
\text { группа }\end{array}$ & $\begin{array}{c}\text { Количество } \\
\text { больных }\end{array}$ & $\begin{array}{c}\text { Депрессия, } \\
\mathbf{n}(\%)\end{array}$ & $\begin{array}{c}\text { Тревога, } \\
\mathbf{n}(\%)\end{array}$ \\
\hline РГЖ & $<40$ лет & 6 & $4(66,6 \pm 18,6)^{*}$ & $6(100 \pm 50)$ \\
& $>40$ лет & 11 & $2(18,2 \pm 9,8)$ & $8(72,7 \pm 24,5)$ \\
РЯ & $<40$ лет & 2 & $2(100 \pm 50)^{*}$ & $2(100 \pm 50)$ \\
РШМ & $>40$ лет & 4 & $1(25 \pm 16,3)$ & $2(50 \pm 19,4)$ \\
& $<40$ лет & 2 & $2(100 \pm 50)^{*}$ & $2(100 \pm 50)$ \\
& $>40$ лет & 5 & $1(20 \pm 14,8)$ & $3(60 \pm 20,8)$ \\
\hline
\end{tabular}

${ }^{*} p<0,05$ по сравнению с возрастной группой $<40$ лет.

\section{выводы}

1. Полученные пилотные результаты указывают на необходимость психологической коррекции пациентов с диагнозом злокачественных новообразований как на начальном этапе лечения, так и после противоопухолевой терапии.
2. Наиболее выраженные явления депрессии и тревоги отмечали у больных после установления диагноза. Специальные методы лечения незначительно снижали эти показатели.

3. Показатели депрессии и тревоги были более выражены у женщин репродуктивного возраста, независимо от типа заболевания.

\section{СПИСОК ИСПОЛЬЗОВАННОЙ ЛИТЕРАТУРЫ}

1. Урванцев, Л.П. Психология соматического больного. Ярославль, 458 с.

2. Саймонтон, К. Психотерапия рака. СПб.: Питер, 288 с.

3. Abraha, H. J., Gielissen, M. F., Verhagen, C. A., \& Knoop, H. (2018). The relationship of fatigue in breast cancer survivors with quality of life and factors to address in psychological interventions: A systematic revie. Clinical Psychology Review, 63(7), 1-11. doi: 10.1016/j.cpr.2018.05.004

4. Гнездилов, А. В. (2001). Психические изменения у онкологических больных. Практическая онкология, 1(5), 5-13. Retrieved from http://rosoncoweb.ru>library> journals $>$ practical oncology $>$ arh005.

5. Backe, I. F., Patil, G. G., Nes, R. B., \& Clench-Aas, J. (2018). The relationship between physical functional limitations, and psychological distress: Considering a possible mediating role of pain, social support and sense of mastery. SSM - Population Health, 4, 153-163. doi: 10.1016/j.ssmph.2017.12.005.

6. Strange, K. S., Kerr, L. R., Andrews, H. N., Emerman, J. T., \& Weinberg, J. (2000). Psychosocial stressors and mammary tumor growth: an animal model. NeurotoxicolTeratology, 22(1), 89-102. doi: 10.1016/s0892-0362(99)00049-5.

7. Pollock, E., Litzelman, K., Wisk, L., \& Witt, W. (2013). Correlates of Physiological and Psychological Stress Among Parents of Childhood Cancer and Brain Tumor Survivors. Academic Pediatrics, 13(2), 105-112. doi: 10.1016/j.acap.2012.11.005.

8. Dessi, A., Orgiano, L., Massa, E., Astara, G., Madeddu, C., Pedditzi, E., \& Scartozzi, M. (2017). Preliminary data for assessing the impact of psychological stress on the development of primitive tumors or relapses of disease. Annals of Oncology, 22(6), 87. doi: org/10.1093/annonc/mdx434.020.

9. Geerse, O., Brandenbarg, D. Kerstjens, H., Berendsen, A., Duijts, S. F. A., Burger, H., ... Hiltermann, T. J. N. (2019). The distress thermometer as a prognostic tool for one-year survival among patients with lung cancer. Lung Cancer, 130(4), 101-107. doi: 10.1016/j.lungcan.2019.02.008

10. Neamtiu, L., Deandrea, S., Pylkkänen, L., Freeman, C., López Alcalde, J., Bramesfeld, A., ... Lerda, D. (2016). Psycho-oncological support for breast cancer patients: A brief overview of breast cancer services certification schemes and national health policies in Europe. The Breast, 29(10), 178-180. doi: 10.1016/j.breast.2016.07.002.

11. Berhili, S., Ouabdelmoumen, A., Sbai, A., Kebdani, T., Benjaafar, N., \& Mezouar, L. (2019). Radical Mastectomy Increases Psychological Distress in Young Breast Cancer Patients: Results of A Cross-sectional Study. Clinical Breast Cancer, 19(1): 160-165. doi: 10.1016/j.clbc.2018.08.013.

Стресові реакції пацієнтів з онкологічною патологією до і після спеціальних методів лікування: пілотні дослідження

\section{О.П. Кузьменко ${ }^{1}$, О.І. Костриба ${ }^{2}$, О.В. Турчак², В.Г. Білик ${ }^{1}$ I.B. Шеремет ${ }^{1}$, С.В. Страшко}

'Національний педагогічний університет ім. М.П. Драгоманова, Київ ${ }^{2}$ Національний інститут раку, Київ

$\boldsymbol{B} \boldsymbol{c m y n}$. Грудна залоза, яєчники і шийка матки є атрибутами жіночого тіла, і їх втрата після операції з приводу раку, безумовно, вважається сильним психотравматичним чинником. Об'єкт $\boldsymbol{i}$ методи дослідження. Для оцінки психологічного статусу в наших дослідженнях використовували Госпітальну шкалу тривоги ідепресіi (Hospital Anxiety and Depression Scale - HADS), оскільки іiі психометричні якості широко продемонстровані у валідаційних дослідженнях у клінічній онкології. Результати. Виразність стресових реакцій на діагноз «рак» залежала як від спеціальних методів лікування, так і від віку пацієнтів. Найбільш сильний прояв депресії та тривоги спостерігався у жінок репродуктивного віку на момент верифікації діагнозу. Висновки. Отримані пілотні результати вказують на необхідність корекції психологічного стану пацієнтів зі злоякісними новоутвореннями, особливо на стадії встановлення діагнозу.

Ключові слова: депресія; тривога; рак грудної залози; рак яєчників; рак шийки матки; репродуктивний вік.

The stress reactions in patients with breast, ovaries and cervix cancer before and after special treatments: a pilot studies

A.P. Kuzmenko ${ }^{1}$, A.I. Kostryba ${ }^{2}$, A.V. Turchak ${ }^{2}$, V.G. Bilyk ${ }^{1}$ I.V. Sheremet ${ }^{1}$, S.V. Strashko ${ }^{1}$

${ }^{1}$ Dragomanov National Pedagogical University. Kiev ${ }^{2}$ National Cancer Institute, Kiev

Introduction. The mammary gland, ovaries and cervix are one of the attributes of the female body and their loss after surgery for cancer is certainly considered a strong psychological traumatic factor. The object and methods of research. In our studies, the Hospital 


\section{Оригінальні статті / Original Articles}

Anxiety and Depression Scale (HADS) scale was used to assess the psychological status, because the psychometric qualities of this scale were demonstrated in validation studies in clinical oncology. Results. The most severe manifestation of depression and anxiety was observed in women of reproductive age at the time of verification of the diagnosis. Findings. The obtained pilot results indicate the need to correct the psychological state of patients with a diagnosis of malignant neoplasms, especially at the stage of diagnosis.

Key words: depression; anxiety; breast cancer; ovarian cancer; cervical cancer, reproductive age.
Адрес:

Кузьменко Александр Петрович

О10зо Киев, ул. Пирогова, 9

Национальный педагогический университет им. М.П. Драгоманова

E-mail:kuzmen_alex@ukr.net

Correspondence: Kuzmenko Alexander 9 Pyrohova str., Kyiv 01030 National Pedagogical Dragomanov University E-mail:kuzmen_alex@ukr.net 